\title{
Labour analgesia: update and literature review
}

\author{
KK Lam *, May KM Leung, Michael G Irwin
}

This article was published on 17 Sep 2020 at www.hkmj.org.

\section{A B S T R A C T}

Pain relief is an important component of modern obstetric care and can be produced by neuraxial, systemic, or inhalational analgesia or various physical techniques. We review the most recent evidence on the efficacy and safety of these techniques. Over the past decade, the availability of safer local anaesthetics, ultra-short acting opioids, combined spinal-epidural needles, patient-controlled analgesic devices, and ultrasound have revolutionised obstetric regional analgesia. Recent meta-analyses have supported epidural analgesia as the most efficacious technique, as it leads to higher maternal satisfaction and good maternal and fetal safety profiles. We examine the controversies and myths concerning the initiation, maintenance, and discontinuation of epidural analgesia. Recent evidence will also be reviewed to address concerns about the effects of epidural analgesia on the rates of instrumental and operative delivery, lower back pain, and breastfeeding. New developments in labour analgesia are also discussed.

\section{Hong Kong Med J 2020;26:413-20 \\ https://doi.org/10.12809/hkmj208632}

KK Lam *, MB, ChB, FHKAM (Anaesthesiology)

MKM Leung, MB, BS, FHKAM (Anaesthesiology)

MG Irwin, MB, ChB, FHKAM (Anaesthesiology)

Department of Anaesthesiology, The University of Hong Kong, Hong Kong

* Corresponding author: dr.patricklam.hk@gmail.com

\section{Introduction}

Labour pain is so notoriously painful that opium and its derivatives have been used in childbirth for several thousand years, along with numerous folk medicines and remedies. Nulliparous women suffer greater sensory pain during the early stage of labour compared with multiparous women, for whom the second stage is more intense. ${ }^{1}$ Labour pain has both visceral and somatic components. ${ }^{2}$ The first stage of labour pain is caused by contraction of the uterus and gradual dilatation of the cervix. The visceral pain is carried by small unmyelinated C-fibres through sympathetic nerves to the T10 to L1 segments of the dorsal horn of the spinal cord. The pain is often referred to as located in the front and back of the lower abdomen and sacrum. Stretching of the vaginal wall, perineum, and vaginal surface of the cervix in the later stage of labour causes ischaemic pain, which is conducted through thick myelinated A fibres in the pudendal and perineal branches of the posterior cutaneous nerve in the thigh to the $\mathrm{S} 2$ to S4 nerve roots, Thus, women who are giving birth feel sharp somatic pain in the perineum.

As well as being unpleasant, labour pain may have harmful effects on the mother and baby, ${ }^{1,3}$ as pain stimulates catecholamine release, which constricts the uterine blood vessels. Pain also causes maternal hyperventilation, resulting in hypocapnia, which further constricts the uterine vessels and decreases the mother's ventilatory drive between contractions, thereby causing the left shift of the maternal oxygen dissociation curve. These factors compromise oxygen supply to the fetus and can lead to fetal hypoxaemia and fetal metabolic acidosis (Fig 1). Premature 'bearing down' can also lead to birth canal trauma and birth injury. Parenteral opioids can exacerbate maternal respiratory depression, whereas regional analgesia can reduce the adverse effects of labour pain on respiration and the sympathetic nervous system. Therefore, good labour analgesia should aim not only to relieve the pain and suffering of the mother but also to decrease fetal acidosis and make the delivery process safer for both the mother and baby. Traditionally, pain relief methods are classified into non-pharmacological, pharmacological, and regional techniques. In this article, we examine the most recent evidence on the efficacy and safety of the commonly available methods.

\section{Non-pharmacological techniques}

Mild labour pain may be reduced by massage, psychological relaxation techniques, transcutaneous electrical nerve stimulation, aromatherapy, hypnosis, sterile water injection, acupuncture, deep breathing, and hydrotherapy. However, most of the evidence on non-drug interventions is based on anecdotal reports from a small number of studies. A Cochrane systematic review reported that immersion and relaxation produced good satisfaction, and both relaxation and acupuncture decreased the use of forceps and ventouse, with acupuncture also decreasing the number of Caesarean sections. ${ }^{4}$ There was insufficient evidence to judge whether or not hypnosis, biofeedback, sterile water injection, aromatherapy, and transcutaneous electrical nerve stimulation are effective. ${ }^{4}$ 


\section{分娩鎮痛：更新和文獻回顧}

林國基、梁家美、Michael G Irwin

疼痛緩解是現代產科護理的重要部分, 可以通過椎管內、全身或吸入 鎮痛或各種非藥物技術達到減痛效果。本文回顧有關技術的有效性和 安全性的最新研究。過去十年, 更安全的局部麻醉藥、超短效鴉片類 藥物、脊柱硬膜外聯合針刺、病人自控鎮痛設備, 以及超聲檢查技術 已徹底改變產科局部的鎮痛方式。近年的著萃分析支持硬膜外鎮痛是 最有效的技術, 因為它可提高產婦的滿意度以及產婦和胎兒的安全。 我們檢視有關開始、維持和停止硬膜外鎮痛的爭議和迷思, 並透過近 年研究探討硬膜外鎮痛對陰道助產和手術分娩率、腰痛和母乳喂養率 影響的憂慮。我們也討論分婏鎮痛的最新進展。

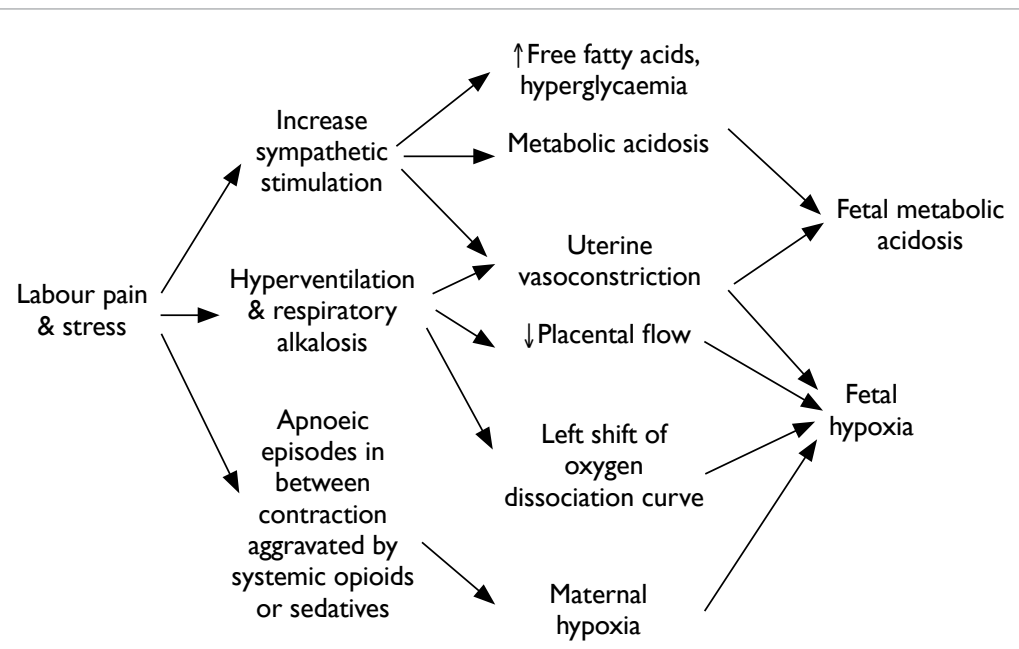

FIG I. Effects of labour pain on mother and fetus

\section{Pharmacological techniques}

Entonox is a mix of $50 \%$ nitrous oxide in oxygen that has been in use for a long time. It has some analgesic efficacy, but many women who used it felt drowsy, nauseous, or were sick. ${ }^{4}$ Nitrous oxide has detrimental effects on vitamin B12 metabolism, and there are valid concerns about occupational exposure to healthcare professionals in the delivery suite, although the use of a proper scavenging system can help. It has the advantage of being easy to use by self-administration, but around $30 \%$ to $40 \%$ of patients found pain relief inadequate with Entonox alone. $^{5}$

Sub-anaesthetic doses $(0.8 \%$ in oxygen) of sevoflurane have been evaluated as an alternative to Entonox. ${ }^{6,7}$ In those studies, despite its lack of analgesic effects and increased level of sedation, most women preferred it to Entonox. It also caused less nausea and vomiting than Entonox. However, there are valid concerns about loss of consciousness, fetal toxicity, and air pollution; therefore, it is not popular.

Intramuscular pethidine is widely prescribed. Pethidine is a potent opioid, making the side-effects of somnolence, nausea, vomiting, and respiratory depression common. It is less effective than epidural analgesia ${ }^{4}$ and cannot be given near the end of the first stage or during the second stage of labour because of its respiratory depressant effects on the baby. It also has a neuroexcitatory metabolite, norpethidine.

Remifentanil, an ultra-short acting opioid with a half-life of about 3 minutes irrespective of the duration of infusion, is usually given intravenously using a patient-controlled analgesic pump. In 2001, we found that the time to first request for rescue analgesia and maternal satisfaction were higher with patient-controlled analgesic remifentanil compared with intramuscular pethidine. There was no sedation, apnoea, or oxygen desaturation in either group, and Apgar scores of the groups were similar. ${ }^{8}$ In 2018, the RESPITE trial showed that remifentanil halved the proportion of epidural conversions compared with intramuscular pethidine. ${ }^{9}$ The pooled risk ratio for rescue analgesia of remifentanil relative to pethidine was 0.54 . The study also reported that remifentanil posed no excessive risk of respiratory depression to the mothers or babies, thus challenging pethidine's routine use as a first-line opioid in the management of labour pain. Although its analgesia is not superior to an epidural, remifentanil is an efficacious alternative for patients who have contra-indications to epidural administration, including back problems, coagulopathy, and fixed cardiac output diseases. Many local and overseas centres have incorporated this option into their labour pain management programmes. The RemiPCA SAFE Network has been established to set standards and monitor maternal and fetal outcomes when remifentanil is used for labour analgesia. ${ }^{10}$

\section{Neuraxial analgesic techniques}

Epidural analgesia, introduced in the 1960s, is still the most effective method of labour pain relief. ${ }^{11}$ It involves placing a very fine catheter into the epidural space for repeat boluses or continuous infusion of local anaesthetics. This allows for continuous pain relief throughout labour and 'top-up' boluses, if required, for operative deliveries. New drugs and technological advancements have improved safety, and our understanding of its effects on obstetric outcomes has been revised (Table 1). Levobupivacaine and ropivacaine are the newest amide local anaesthetics, and they are less cardiotoxic than bupivacaine. Traditionally, a high concentration of local anaesthetic (eg, 0.2\%-0.25\% bupivacaine) has been used to maintain labour 
TABLE I. Advanced techniques for regional labour analgesia

Initiation: aim to suit the needs of different stages of labour

1. Combined spinal-epidural technique

2. Preprocedural or real-time ultrasound guidance

3. Continuous intrathecal analgesia

4. Single-shot spinal analgesia

Maintenance: aim to minimise lower limb motor blockage and incidence of breakthrough pain

1. Mixture of low-dose local anaesthetic and lipophilic opioid

2. Continuous infusion

3. Patient-controlled epidural analgesia

4. Programmed intermittent boluses

5. Computerised-integrated background infusion

epidural analgesia. Over the years, the adoption of a lower concentration of local anaesthetic (0.0625\%-0.1\%) and lipophilic opioids (fentanyl or sufentanil) has lessened side-effects such as motor blockage and hypotension. ${ }^{12}$ These drugs have made it possible for women to walk or move around more easily in bed and retain a mild sensation of uterine contraction and urgency of bearing down, thereby facilitating pushing the baby out in the second stage of labour. In the Comparative Obstetric Mobile Epidural Trial study, the use of low-dose infusion significantly reduced the incidence of assisted vaginal delivery. ${ }^{13}$ Meta-analysis showed that a lower concentration of local anaesthetic reduces the incidence of assisted vaginal delivery and urinary retention and shortens the second stage compared with a higher concentration. ${ }^{14}$ A 2018 Cochrane review stated that this type of epidural analgesia has no adverse impact on the proportions of Caesarean section, long-term backache, or neonatal outcomes. ${ }^{11}$

\section{Combined spinal-epidural technique}

In the 'needle-through-needle' combined spinalepidural (CSE) technique, a 25- or 27-G pencil point spinal needle with a locking device is inserted through the epidural needle that allows the deposition of a small dose of local anaesthetic, with or without opioids, into the cerebrospinal fluid in the intrathecal space. The onset of analgesia is rapid. An epidural catheter is then threaded through the epidural needle after withdrawing the spinal needle. A review of the complications has concluded that CSE is equally safe to a conventional epidural. ${ }^{15}$ The use of CSE has increased relative to that of the conventional epidural technique, as it has a quicker onset of analgesia in mothers with severe pain, those in the advanced stage of labour, and those who are multiparous. The technique also improves the success of correct functioning epidural catheter placement by prior verification of placement in the subarachnoid space with the spinal needle. ${ }^{16}$ Despite the increasingly widespread use of this technique and numerous published investigations, the optimal intrathecal drug regimen has not yet been determined. The disadvantage of CSE is immediate uncertainty about whether the epidural is working because of the initial effects of spinal analgesia. However, a 2016 study refuted this and favoured CSE earlier detection of failed epidural analgesia. ${ }^{17}$ The use of a 27-G spinal needle is preferred, as its small size is associated with a lower risk of post-dural puncture headache. ${ }^{18}$ Although there is faster onset of analgesia, the effects on maternal satisfaction are controversial. A systematic review found no differences in maternal satisfaction, mode of delivery, or ambulatory ability between CSE and the conventional epidural technique. ${ }^{19}$ Subsequently, the choice between conventional epidural and CSE has often been dictated by the clinical situation, institutional protocols, available equipment, and practitioner preference/experience.

\section{Continuous intrathecal technique}

In continuous intrathecal labour analgesia, local anaesthetic with or without opioids is directly deposited into the intrathecal space using a 23- to 28-G microcatheter. This technique can provide rapid analgesia or anaesthesia and higher maternal satisfaction with less use of local anaesthetic, but it is also associated with more technical difficulties and catheter failure compared with epidural analgesia. It is theoretically advantageous in the management of morbidly obese patients, patients with significant co-morbidities who cannot tolerate haemodynamic instability, and patients with potentially difficult airways who undergo Caesarean section, as it allows gradual titration and slower onset of subarachnoid blockage. ${ }^{20}$ This technique is still uncommonly used because of various concerns including post-dural puncture headache and neuraxial infection. Further studies are required to assess whether it can assist in the management of patients with conditions that make neuraxial labour analgesia challenging.

\section{Maintenance of neuraxial analgesia}

Once an epidural catheter is placed, analgesia can be maintained by intermittent top-ups, continuous infusion, patient-controlled analgesia, or programmed intermittent epidural boluses (PIEB). Continuous infusion technique became popular in the early 1980s. This delivery method reduced the variability of analgesia during labour, especially when high concentrations of local anaesthetics were replaced by low concentrations with the addition of a lipophilic opioid. Unfortunately, this modality does not suit all patients despite many combinations of 
infusion rate, local anaesthetic concentration, and additives having been investigated. Many patients still require clinician-initiated top-ups or experience unacceptable motor blockage.

\section{Patient-controlled epidural analgesia}

Patient-controlled epidural analgesia (PCEA) was first described in $1988 .{ }^{21}$ Boluses of 4 to $8 \mathrm{~mL}$ of epidural mixture are delivered on patient demand with a lockout interval of 10 to 20 minutes. As labour pain has highly variable intensity, and the character of the pain often changes as it progresses, it makes sense that patients may be the best managers of their own pain relief. There is recent evidence that genetic polymorphism may also affect the patient's labour progress and response to labour analgesia. One example is the $\mathrm{Mu}$ opioid receptor gene single-nucleotide polymorphism (OPRM1, A118G), which is believed to be present in $30 \%$ of women in labour and may affect the response to neuraxial opioids. $^{22,23}$ Administration of PCEA allows for some self-titration. Over the past 20 years, PCEA has been widely studied and the technique refined. High-volume, dilute local anaesthetic solutions with a continuous background infusion appear to be the best PCEA regimen. ${ }^{24}$ The American Society of Anesthesiologists practice guidelines for obstetric anaesthesia advise that basal infusion improves analgesia when provided as part of a PCEA regimen. ${ }^{25}$ Studies have also shown that PCEA requires less anaesthesia intervention, lower doses of local anaesthetic, and produces less motor blockage than continuous epidural infusion. ${ }^{26,27}$ Although PCEA delivery devices tend to be more expensive than continuous infusion pumps, the technique may have important benefits. The optimum method of administration requires communication with both the midwife and the patient.

\section{Computer-integrated patient-controlled epidural analgesia}

An alternative approach to determining the background infusion rate during PCEA is the use of a computer programme to automatically adjust the background infusion rate according to the amount of local anaesthetic used in the previous hour. A laptop computer is connected to a PCEA pump. In theory, a system that responds to a patient's analgesic requirements should improve efficacy while minimising the amount of local anaesthetic used for background infusions. Initial studies with this system have been encouraging. In a study comparing demand-only PCEA with computer-integrated background infusion PCEA (CIPCEA), the CIPCEA group had similar local anaesthetic consumption but increased maternal satisfaction. ${ }^{28}$ Another study found that CIPCEA reduced the incidence of breakthrough pain without increasing drug consumption compared with continuous epidural infusion. ${ }^{29}$ When CIPCEA was compared with PCEA using fixed-rate continuous infusion, the CIPCEA group had higher maternal satisfaction, whereas local anaesthetic consumption, visual analogue pain scores, and incidence of breakthrough pain were similar between the two groups. ${ }^{30}$ Therefore, an adjustable background infusion appears to increase maternal satisfaction and may further reduce the incidence of breakthrough pain without increasing local anaesthetic consumption.

\section{Programmed intermittent epidural boluses}

Programmed intermittent epidural boluses is a novel technology in which boluses of epidural mixture are delivered at predetermined intervals. Improved analgesia may be offered by PIEB, as the local anaesthetic is administered in boluses under high driving pressure, which can disperse the solution more widely than continuous infusion ${ }^{31}$ with multiorifice catheters. ${ }^{32}$ A system has been developed in which a computer delivers both automated and manual boluses. The authors demonstrated that this 'programmed intermittent mandatory epidural bolus' with a PCEA regimen provided advantages over a PCEA plus background infusion regimen: the former used less local anaesthetic dose, but resulted in a higher maternal satisfaction and a longer duration of analgesia. However, there was no difference in the incidence of breakthrough pain between the two groups. ${ }^{33,34}$ In 2012 and 2014, respectively, Health Canada and the United States Food and Drug Administration approved PIEB combined with PCEA (CADD Solis Epidural Pump, Smiths Medical, St Paul [MN], United States) for clinical use. ${ }^{35} \mathrm{~A} 2013$ systematic review investigating PIEB for maintenance of labour analgesia that included nine randomised controlled trials with 694 patients $^{36}$ showed that the vast majority of studies associated PIEB with decreased local anaesthetic consumption, improved maternal satisfaction scores, decreased instrumental delivery, and lessened need for anaesthesia intervention. A recent trial confirmed that reduced motor blockage was associated with PIEB, ${ }^{37}$ although that study could not identify other significant outcomes.

\section{Ultrasound}

Although ultrasound is widely used in the placement of central venous catheters and peripheral nerve blockage, it is less commonly used in neuraxial analgesia for obstetric patients. It can be used either before the procedure to study the site of needle entry and the depth of the epidural space or for real-time needle guidance (Fig 2). Although the preprocedural use of ultrasound in normal pregnant 


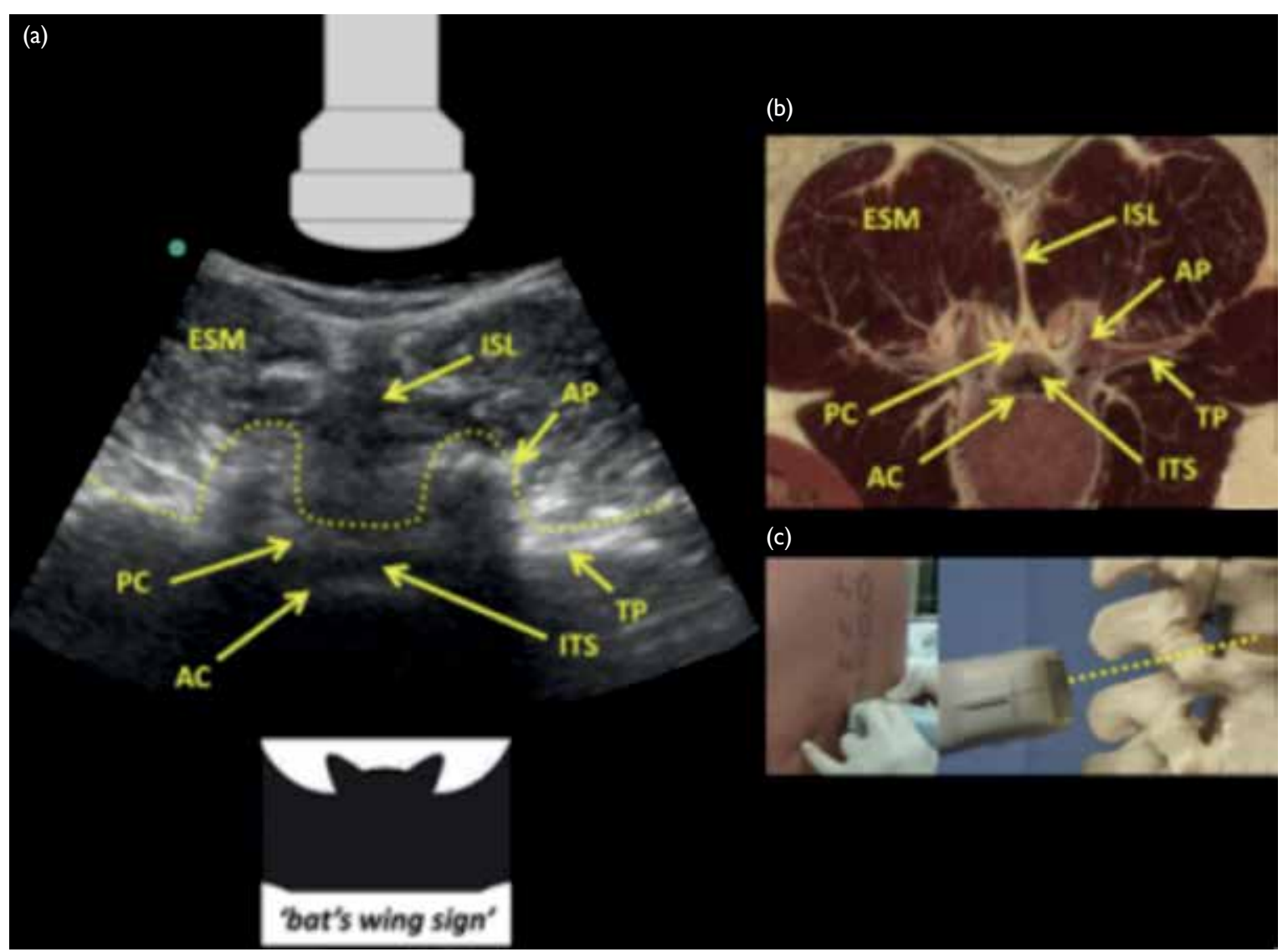

FIG 2. Lumbar spine. (a) Transverse interlaminar view; (b) anatomical section (virtual slice extraction from visiblehuman.epfl.ch); and (c) ultrasound probe orientation. Image courtesy of Chin KJ. Ultrasound-guided lumbar central neuraxial block. BJA Education 2016;16:213-20.

Abbreviations: $\mathrm{AC}=$ anterior complex; $\mathrm{AP}=$ articular process; $\mathrm{ESM}=$ erector spinae muscle; $I S L=$ interspinous ligament; ITS = intrathecal space; $\mathrm{PC}=$ posterior complex; TP $=$ transverse process

mothers seems to have limited efficacy among both experienced clinicians ${ }^{38}$ and trainees, ${ }^{39}$ some study findings have suggested that it is a useful tool ${ }^{40}$ to consider in obese patients ${ }^{41}$ or those with lumbar spine problems. In 2008, the United Kingdom's National Institute for Health and Care Excellence determined that sufficient evidence had been published to support the routine use of 'ultrasound to facilitate the catheterisation of the epidural space. ${ }^{42}$ In March 2016, the American Society of Regional Anesthesia and Pain Medicine ${ }^{43}$ published the second evidence-based medicine assessment of ultrasoundguided regional anaesthesia to 'enable practitioners to make an informed evaluation regarding the role of ultrasound-guided regional anaesthesia in their practice. A high-quality review article by Arzola outlined the controversies, advantages, and practical applications of preprocedural ultrasound in obstetric patients. $^{44}$

\section{Intralipid infusion} Neuraxial analgesia is now also safer with the in a shorter duration of labour than systemic availability of intralipid as an antidote for local anaesthetic toxicity. ${ }^{45,46}$ Intralipid binds with amide local anaesthetic molecules in the plasma, thereby decreasing the free fraction available to bind with cardiac muscle. It has become widely adopted as part of the resuscitation protocol for local anaesthetic-caused systemic toxicity and should be readily available in all delivery units where neuraxial analgesia is practised. It is given intravenously by boluses followed by continuous infusion according to body weight (Table 2).

\section{When should an epidural catheter be sited?}

Previous concerns that early epidural initiation (when cervical dilatation $<4 \mathrm{~cm}$ ) would increase the rate of instrumental delivery and Caesarean section have been alleviated by more recent research. Wong et $\mathrm{al}^{47}$ found that neuraxial analgesia in early labour did not increase the rate of Caesarean delivery but provided better analgesia and resulted 
TABLE 2. Management of local anaesthetic systemic toxicity

Circulatory arrest

1. Cardiopulmonary resuscitation and advanced cardiac life support

2. Manage arrhythmia (do not use lidocaine)

3. Consider cardiopulmonary bypass in severe cases

4. Initial intravenous bolus injection of $20 \%$ lipid emulsion $1.5 \mathrm{~mL} / \mathrm{kg}$ over 1 minute, and then initiate intravenous infusion of $20 \%$ lipid emulsion at $0.25 \mathrm{~mL} / \mathrm{kg} /$ minute. Lipid emulsion therapy can be administered via peripheral or central line

5. After 5 minutes, administer two repeat boluses (maximum of three boluses) if cardiac stability has not been restored or adequate circulation deteriorates. Leave 5 minutes between boluses. Double infusion rate to $0.5 \mathrm{~L} / \mathrm{kg} / \mathrm{minute}$ if no clinical improvement or deterioration occurs. Continue infusion until clinical stability and adequate circulation are restored

6. Maximum dose of lipid emulsion: $12 \mathrm{~mL} / \mathrm{kg}$

- Bolus injection is key to rapid clinical improvement, as a large mass of lipid is apparently necessary to achieve the desired effect

- Given that the lipid infusion must circulate to the coronary vascular bed, high-quality basic life support is a necessary element of lipid resuscitation in the setting of a low-output state

Without circulatory arrest

1. Use conventional therapy to treat hypotension, bradycardia, or tachyarrhythmia and consider intravenous lipid emulsion therapy

2. Monitor patients overnight for any signs of cardiac toxicity

analgesia. The latest Cochrane review indicated that there is abundant high-quality evidence that early and late epidural initiation have similar effects on all measured outcomes. ${ }^{48}$ The American College of Obstetricians and Gynaecologists and the American Society of Anesthesiologists ${ }^{49}$ have also jointly emphasised that there is no need to wait until cervical dilation has reached 4 to $5 \mathrm{~cm}$ and stated that 'maternal request is a sufficient indication for pain relief in labour.50 When delivery is imminent, the decision to offer regional anaesthesia should be individualised and depends on various factors including a woman's parity, fetal condition, and whether a prolonged second stage is expected, such as malposition of the fetus or macrosomia. The Royal College of Anaesthetists recommends that the time from epidural request to the anaesthetist attending should not exceed 30 minutes, after which a second anaesthetist should be available. ${ }^{51}$

\section{When should epidural analgesia be terminated?}

There is insufficient evidence to support the discontinuation of epidural analgesia late in labour as a means to reduce adverse delivery outcomes. ${ }^{52}$ Doing so also increases the rate of inadequate pain relief in the second stage of labour. A meta-analysis of high-quality studies did not show significant differences in outcomes with immediate and delayed pushing in the second stage of labour. ${ }^{53}$

\section{Other effects}

The effects of neuraxial analgesia on successful breastfeeding have been evaluated in several studies with controversial results. A recent large, randomised, double-blind, controlled trial showed that epidural solutions containing fentanyl concentrations as high as $2 \mu \mathrm{g} / \mathrm{mL}$ did not affect breastfeeding rates at 6 weeks postpartum. ${ }^{54}$ The results correlated with those of another study investigating women with previous breastfeeding experience, as both studies showed no difference in the breastfeeding rates at 6 weeks postpartum between groups of women who did and did not receive epidural analgesia. ${ }^{55}$ Therefore, factors other than epidural and fentanyl administration can affect the successful breastfeeding rate.

The association of maternal fever with epidural analgesia has remained an area of clinical and research interest. ${ }^{56}$ A 2016 expert panel defined maternal fever as maternal temperature of $\geq 38^{\circ} \mathrm{C}$ measured orally for two readings 30 minutes apart. ${ }^{57}$ Up to one third of mothers may be affected, and the aetiology and prophylactic prevention are still not well understood, although the local anaesthetic used for epidural analgesia is a likely culprit. Sterile inflammation and activation of inflammasomes probably play a role, ${ }^{58}$ and this is an area of ongoing research. ${ }^{59}$

\section{Conclusions}

Epidural analgesia remains the best method of relieving pain during labour. Advances in technology have made it even safer than before. In the absence of any medical contra-indications, maternal request is a sufficient indication to initiate epidural analgesia, and if it is properly conducted, it can be considered at any stage of labour without affecting the rate of instrumental or Caesarean delivery. Future 
improvements may lie in preventing breakthrough pain via interaction with various closed-loop feedback drug delivery systems. Remifentanil-based opioid techniques are becoming a popular alternative if epidural is contra-indicated.

\section{Author contributions}

All authors contributed to the concept of study, drafting of the manuscript, and critical revision of the manuscript for important intellectual content. All authors had full access to the data, contributed to the study, approved the final version for publication, and take responsibility for its accuracy and integrity.

\section{Conflicts of interest}

As an editor of the journal, MG Irwin was not involved in the peer review process of the article. The other authors have no conflicts of interest to disclose.

\section{Acknowledgement}

The authors thank Prof Ki-jinn Chin, Associate Professor, Department of Anesthesia, Toronto Western Hospital, University of Toronto for permission to use the image in Figure 2.

\section{Funding/support}

This research received no specific grant from any funding agency in the public, commercial, or not-for-profit sectors.

\section{References}

1. Labor S, Maguire S. The pain of labour. Rev Pain 2008;2:159.

2. Rowlands S, Permezel M. Physiology of pain in labour Bailliere Clin Obstet Gynaecol 1998;12:347-62.

3. Wong CA. Advances in labor analgesia. Int J Womens Health 2009;1:139-54.

4. Jones L, Othman M, Dowswell T, et al. Pain management for women in labour: an overview of systematic reviews. Cochrane Database Syst Rev 2012;(3):CD009234.

5. Carstoniu J, Levytam S, Norman P, Daley D, Katz J, Sandler AN. Nitrous oxide in early labor safety and analgesic efficacy assessed by a double-blind, placebocontrolled study. Anesthesiology 1994;80:30-5.

6. Yeo ST, Holdcroft A, Yentis SM, Stewart A. Analgesia with sevoflurane during labour: i. Determination of the optimum concentration. Br J Anaesth 2007;98:105-9.

7. Yeo ST, Holdcroft A, Yentis SM, Stewart A, Bassett P. Analgesia with sevoflurane during labour: ii. Sevoflurane compared with Entonox for labour analgesia. Br J Anaesth 2007;98:110-5.

8. Ng TK, Cheng BC, Chan WS, Lam KK, Chan MT. A doubleblind randomised comparison of intravenous patientcontrolled remifentanil with intramuscular pethidine for labour analgesia. Anaesthesia 2011;66:796-801.

9. Wilson MJ, MacArthur C, Hewitt CA, et al. Intravenous remifentanil patient-controlled analgesia versus intramuscular pethidine for pain relief in labour (RESPITE): an open-label, multicentre, randomised controlled trial. Lancet 2018;392:662-72.

10. Melber AA, Jelting Y, Huber M, et al. Remifentanil patientcontrolled analgesia in labour: six-year audit of outcome data of the RemiPCA SAFE Network (2010-2015). Int J Obstet Anesth 2019;39:12-21.

11. Anim-Somuah M, Smyth RM, Cyna AM, Cuthbert A. Epidural versus non-epidural or no analgesia for pain management in labour. Cochrane Database Syst Rev 2018;(5):CD000331.

12. Sharma RM, Setlur R, Bhargava AK, Vardhan S. Walking epidural: an effective method of labour pain relief. Med J Armed Forces India 2007;63:44-6.

13. Comparative Obstetric Mobile Epidural Trial (COMET) Study Group UK. Effect of low-dose mobile versus traditional epidural techniques on mode of delivery: a randomised controlled trial. Lancet 2001;358:19-23.

14. Sultan P, Murphy C, Halpern S, Carvalho B. The effect of low concentrations versus high concentrations of local anesthetics for labour analgesia on obstetric and anesthetic outcomes: a meta-analysis. Can J Anaesth 2013;60:840-54.

15. Skupski DW, Abramovitz S, Samuels J, Pressimone V, Kjaer K. Adverse effects of combined spinal-epidural versus traditional epidural analgesia during labor. Int J Gynecol Obstet 2009;106:242-5.

16. Norris MC, Fogel ST, Conway-Long C. Combined spinalepidural versus epidural labor analgesia. Anesthesiology 2001;95:913-20.

17. Booth JM, Pan JC, Ross VH, Russell GB, Harris LC, Pan PH. Combined spinal epidural technique for labor analgesia does not delay recognition of epidural catheter failures: a single-center retrospective cohort survival analysis. Anesthesiology 2016;125:516-24.

18. Landau R, Ciliberto CF, Goodman SR, Kim-Lo SH, Smiley RM. Complications with 25-gauge and 27-gauge Whitacre needles during combined spinal-epidural analgesia in labor. Int J Obstet Anesth 2001;10:168-71.

19. Simmons SW, Taghizadeh N, Dennis AT, Hughes D, Cyna AM. Combined spinal-epidural versus epidural analgesia in labour. Cochrane Database Syst Rev 2012;(10):CD003401.

20. Drasner K, Smiley R. Continuous spinal analgesia for labor and delivery: a born-again technique? Anesthesiology 2008;108:184-6.

21. Gambling DR, Yu P, Cole C, McMorland GH, Palmer L. A comparative study of patient controlled epidural analgesia (PCEA) and continuous infusion epidural analgesia (CIEA) during labour. Can J Anaesth 1988;35:249-54.

22. Landau R, Cahana A, Smiley RM, Antonarakis SE, Blouin JL. Genetic variability of $\mu$-opioid receptor in an obstetric population. Anesthesiology 2004;100:1030-3.

23. Sia AT, Lim Y, Lim EC, et al. A118G single nucleotide polymorphism of human $\mu$-opioid receptor gene influences pain perception and patient-controlled intravenous morphine consumption after intrathecal morphine for postcesarean analgesia. Anesthesiology 2008;109:520-6.

24. Halpern SH, Carvalho B. Patient-controlled epidural analgesia for labor. Anesth Analg 2009;108:921-8.

25. American Society of Anesthesiologists Task Force on Obstetric Anesthesia. Practice guidelines for obstetric anesthesia: an updated report by the American Society of Anesthesiologists Task Force on Obstetric Anesthesia. Anesthesiology 2007;106:843-63.

26. van der Vyver M, Halpern S, Joseph G. Patient-controlled epidural analgesia versus continuous infusion for labour analgesia: a meta-analysis. Br J Anaesth 2002;89:459-65.

27. D'Angelo R. New techniques for labor analgesia: PCEA and CSE. Clin Obstet Gynecol 2003;46:623-32. 
28. Lim Y, Sia AT, Ocampo CE. Comparison of computer integrated patient controlled epidural analgesia vs. conventional patient controlled epidural analgesia for pain relief in labour. Anaesthesia 2006;61:339-44.

29. Sia AT, Lim Y, Ocampo CE. Computer-integrated patientcontrolled epidural analgesia: a preliminary study on a novel approach of providing pain relief in labour. Singapore Med J 2006;47:951-6.

30. Sng BL, Sia AT, Lim Y, Woo D, Ocampo C. Comparison of computer-integrated patient-controlled epidural analgesia and patient-controlled epidural analgesia with a basal infusion for labour and delivery. Anaesth Intensive Care 2009;37:46-53.

31. Hogan Q. Distribution of solution in the epidural space: examination by cryomicrotome section. Reg Anesth Pain Med 2002;27:150-6.

32. Duncan LA, Fried MJ, Lee A, Wildsmith JA. Comparison of continuous and intermittent administration of extradural bupivacaine for analgesia after lower abdominal surgery. $\mathrm{Br}$ J Anaesth 1998;80:7-10.

33. Sia AT, Lim Y, Ocampo C. A comparison of a basal infusion with automated mandatory boluses in parturientcontrolled epidural analgesia during labor. Anesth Analg 2007;104:673-8.

34. Leo S, Sia AT. Maintaining labour epidural analgesia: what is the best option? Curr Opin Anaesthesiol 2008;21:263-9.

35. Carvalho B, George RB, Cobb B, McKenzie C, Riley ET. Implementation of programmed intermittent epidural bolus for the maintenance of labor analgesia. Anesth Analg 2016;123:965-71.

36. George RB, Allen TK, Habib AS. Intermittent epidural bolus compared with continuous epidural infusions for labor analgesia: a systematic review and meta-analysis. Anesth Analg 2013;116:133-44.

37. Ojo OA, Mehdiratta JE, Gamez BH, Hunting J, Habib AS. Comparison of programmed intermittent epidural boluses with continuous epidural infusion for the maintenance of labor analgesia: a randomized, controlled, double-blind study. Anesth Analg 2020;130:426-35.

38. Ansari T, Yousef A, El Gamassy A, Fayez M. Ultrasoundguided spinal anaesthesia in obstetrics: is there an advantage over the landmark technique in patients with easily palpable spines? Int J Obstet Anesth 2014;23:213-6.

39. Arzola C, Mikhael R, Margarido C, Carvalho JC. Spinal ultrasound versus palpation for epidural catheter insertion in labour: a randomised controlled trial. Eur J Anaesthesiol 2015;32:499-505.

40. Perlas A, Chaparro LE, Chin KJ. Lumbar neuraxial ultrasound for spinal and epidural anesthesia: a systematic review and meta-analysis. Reg Anesth Pain Med 2016;41:251-60.

41. Creaney M, Mullane D, Casby C, Tan T. Ultrasound to identify the lumbar space in women with impalpable bony landmarks presenting for elective Caesarean delivery under spinal anaesthesia: a randomised trial. Int J Obstet Anesth 2016;28:12-6.

42. National Institute for Health and Care Excellence (NICE). Interventional procedures guidance (IPG249): Ultrasoundguided catheterisation of the epidural space. 23 Jan 2008.

43. Neal JM, Brull R, Horn JL, et al. The Second American
Society of Regional Anesthesia and Pain Medicine evidence-based medicine assessment of ultrasound-guided regional anesthesia: executive summary. Reg Anesth Pain Med 2016;41:181-94.

44. Arzola C. Preprocedure ultrasonography before initiating a neuraxial anesthetic procedure. Anesth Analg 2017;124:712-3.

45. Kosh MC, Miller AD, Michels JE. Intravenous lipid emulsion for treatment of local anesthetic toxicity. Ther Clin Risk Manag 2010;6:449-51.

46. Weinberg GL. Lipid emulsion infusion: resuscitation for local anesthetic and other drug overdose. Anesthesiology 2012;117:180-7.

47. Wong CA, Scavone BM, Peaceman AM, et al. The risk of Cesarean delivery with neuraxial analgesia given early versus late in labor. N Engl J Med 2005;352:655-65.

48. Sng BL, Leong WL, Zeng Y, et al. Early versus late initiation of epidural analgesia for labour. Cochrane Database Syst Rev 2014;(10):CD007238.

49. Lim G, Levine MD, Mascha EJ, Wasan AD. Labor pain, analgesia, and postpartum depression: are we asking the right questions? Anesth Analg 2020;130:610-4.

50. Rendon KL, Wheeler V. Epidural analgesia and risk of Cesarean delivery. Am Fam Physician 2018 Nov 1;98:Online.

51. Chapter 9: Guidelines for the provision of anaesthesia services (GPAS). Guidelines for the Provision of Anaesthesia Services for an Obstetric Population. Royal College of Anaesthetists; 2020: 9.

52. Torvaldsen S, Roberts CL, Bell JC, Raynes-Greenow CH. Discontinuation of epidural analgesia late in labour for reducing the adverse delivery outcomes associated with epidural analgesia. Cochrane Database Syst Review 2004;(4):CD004457.

53. Tuuli MG, Frey HA, Odibo AO, Macones GA, Cahill AG. Immediate compared with delayed pushing in the second stage of labor: a systematic review and meta-analysis. Obstet Gynecol 2012;120:660-8.

54. Lee AI, McCarthy RJ, Toledo P, Jones MJ, White N, Wong CA. Epidural labor analgesia-fentanyl dose and breastfeeding success: a randomized clinical trial. Anesthesiology 2017;127:614-24.

55. Orbach-Zinger S, Landau R, Davis A, et al. The effect of labor epidural analgesia on breastfeeding outcomes: a prospective observational cohort study in a mixed-parity cohort. Anesth Analg 2019;129:784-91.

56. Chan JJ, Dabas R, Han RN, Sng BL. Fever during labour epidural analgesia. Trends in Anaesthesia and Crit Care 2018;20:21-5.

57. Higgins RD, Saade G, Polin RA, et al. Evaluation and management of women and newborns with a maternal diagnosis of chorioamnionitis: summary of a workshop. Obstet Gynecol 2016;127:426-36.

58. Sultan P, David AL, Fernando R, Ackland GL. Inflammation and epidural-related maternal fever: proposed mechanisms. Anesth Analg 2016;122:1546-53.

59. Lim G, Facco FL, Nathan N, Waters JH, Wong CA, Eltzschig HK. A review of the impact of obstetric anesthesia on maternal and neonatal outcomes. Anesthesiology 2018;129:192-215. 